OPEN ACCESS

Edited by:

Isabel Merida,

Spanish National Research Council,

Spain

Reviewed by:

Narayanan Parameswaran,

Michigan State University, USA

Ignacio Rubio

University of Jena, Germany

Gianluca Baldanzi,

Università Piemonte Orientale, Italy

${ }^{*}$ Correspondence:

Matthew J. Riese

matthew.riese@bcw.edu

Steven M. Albelda

albelda@mail.med.upenn.edu

Specialty section:

This article was submitted to

Signaling,

a section of the journal

Frontiers in Cell and Developmental

Biology

Received: 28 July 2016 Accepted: 14 September 2016

Published: 17 October 2016

Citation:

Riese MJ, Moon EK, Johnson BD and Albelda SM (2016) Diacylglycerol Kinases (DGKs): Novel Targets for Improving T Cell Activity in Cancer.

Front. Cell Dev. Biol. 4:108

doi: 10.3389/fcell.2016.00108

\section{Diacylglycerol Kinases (DGKs): Novel Targets for Improving T Cell Activity in Cancer}

\author{
Matthew J. Riese ${ }^{1,2 *}$, Edmund K. Moon ${ }^{3}$, Bryon D. Johnson ${ }^{4}$ and Steven M. Albelda ${ }^{3 *}$ \\ ${ }^{1}$ Division of Hematology/Oncology, Department of Medicine, Medical College of Wisconsin, Milwaukee, WI, USA, ${ }^{2}$ Blood \\ Center of Wisconsin, Blood Research Institute, Milwaukee, WI, USA, ${ }^{3}$ Division of Pulmonary, Allergy, and Critical Care, \\ Department of Medicine, University of Pennsylvania, Philadelphia, PA, USA, ${ }^{4}$ Division of Hematology/Oncology/Transplant, \\ Department of Pediatrics, Medical College of Wisconsin, Milwaukee, WI, USA
}

Diacylglycerol kinases (DGKs) are a family of enzymes that catalyze the metabolism of

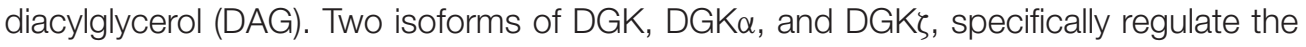
pool of DAG that is generated as a second messenger after stimulation of the $T$ cell receptor (TCR). Deletion of either isoform in mouse models results in $\mathrm{T}$ cells bearing a hyperresponsive phenotype and enhanced $T$ cell activity against malignancy. Whereas, DGK $\zeta$ appears to be the dominant isoform in T cells, rationale exists for targeting both isoforms individually or coordinately. Additional work is needed to rigorously identify the molecular changes that result from deletion of DGKs in order to understand how DAG contributes to $T$ cell activation, the effect of DGK inhibition in human T cells, and to rationally develop combined immunotherapeutic strategies that target DGKs.

Keywords: diacylglycerol, diacylglycerol kinase, immunotherapy, CD8+ T cell, T cell receptor

\section{DIACYLGLYCEROL KINASES IN T CELL RECEPTOR SIGNAL TRANSDUCTION}

Diacylglycerol kinases (DGKs) represent a family of enzymes that catalyze phosphorylation of the membrane lipid sn-1,2 diacylglycerol (DAG) to form phosphatidic acid (PA) (Eichmann and Lass, 2015). In T cells, DAG is formed downstream of the T cell receptor (TCR) after activation of the gamma 1 isoform of phospholipase $\mathrm{C}(\mathrm{PLC} \gamma 1)$ and cleavage of phosphatidylinositol 4,5-biphosphate $\left(\mathrm{PIP}_{2}\right)$ into DAG and an additional second messenger, inositol 1,4,5-triphosphate $\left(\mathrm{IP}_{3}\right)$ (Krishna and Zhong, 2013). Whereas, $\mathrm{IP}_{3}$ is important in facilitating release of calcium from the endoplasmic reticulum, DAG interacts with other proteins important in TCR signal transduction, such as Protein kinase C (predominantly $\theta$ isoform in $\mathrm{T}$ cells, but also isoforms $\varepsilon$ and $\eta$; Quann et al., 2011) and the Ras activating protein RasGRP1 (Krishna and Zhong, 2013). Biochemically, targeting the activity of DGKs in T cells, either by germline deletion, or with chemical inhibitors, results in enhanced and sustained signaling downstream of $\mathrm{T}$ cells, as assessed by prolonged phosphorylation of downstream molecules, such as extracellular signal-related kinases 1/2 (ERK1/2; Zhong et al., 2003; Olenchock et al., 2006; Riese et al., 2011). Although,

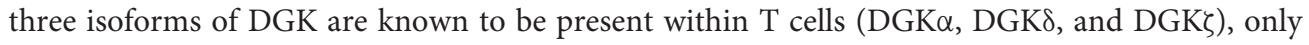
two, DGK $\alpha$ and DGK $\zeta$, are thought to play an important role in facilitating DAG metabolism downstream of the TCR (Joshi and Koretzky, 2013). The function of DGK $\delta$ is unknown in T cells; its role in facilitating metabolic flexibility between lipid and carbohydrate utilization suggest that it may regulate pools of DAG unrelated to TCR signaling (Chibalin et al., 2008). The signaling 
changes resulting from the absence of DGK $\alpha$ or DGK $\zeta$ alter the transcriptional program of activated $\mathrm{T}$ cells. For instance, generation of the transcription factor AP1, which is dependent on Ras/ERK signaling, is decreased in stimulated Jurkat $\mathrm{T}$ cells overexpressing DGKל (Zhong et al., 2002). Similarly, NF$\kappa \mathrm{B}$ (nuclear factor kappa-ligh-chain-enhancer of activated $\mathrm{B}$ cells), a critical transcription factor activated downstream of PKC $\theta$ in T cells, is present at increased levels after stimulation of DGK $\zeta$-deficient lymphocytes as compared to DGK $\zeta$-replete cells (Schmidt et al., 2013), though other data suggests that the regulation of NF- $\kappa \mathrm{B}$ may, in some instances, be positively regulated by DGKs (Yang et al., 2016).

The change in activation of transcription factors in stimulated $\mathrm{T}$ cells after manipulation of DGK activity correlates with changes in $\mathrm{T}$ cell activation markers and function. For instance, overexpression of $\mathrm{DGK} \alpha$ or $\mathrm{DGK} \zeta$ in Jurkat $\mathrm{T}$ cells results in decreased expression of the activation marker CD69 after stimulation through the TCR complex (Sanjuán et al., 2001; Zhong et al., 2002), and overexpression of DGK $\alpha$ induces a state of decreased functional activity resembling an anergy-like state (Zha et al., 2006). In contrast, deletion of DGK $\alpha$ or DGK $\zeta$ results in T cells with enhanced production of effector cytokines, such as IL2 and IFN $\gamma$, and enhanced proliferation (Zhong et al., 2003; Olenchock et al., 2006). Inhibition of DGK $\alpha$ also allows T cells to overcome TCR signaling defects present in human Xlinked lymphoproliferative disease (XLP-1) resulting from the loss of SAP [signaling lymphocytic activation molecule (SLAM)associated protein (Baldanzi et al., 2011; Ruffo et al., 2016)], along with uncontrolled effector $\mathrm{T}$ cell expansion after exposure to Epstein Barr virus (EBV) characteristic of this disease (Ruffo et al., 2016).

\section{TARGETING DIACYLGLYCEROL KINASES TO ENHANCE T CELL ANTI-TUMOR ACTIVITY}

Given the enhanced functional activity conferred by loss of DGKs in $\mathrm{T}$ cells, our group and others have tested the hypothesis that these proteins may serve as useful targets for enhancing $\mathrm{T}$ cell anti-tumor activity. Recently, strategies to target negative regulators of $\mathrm{T}$ cells to enhance their anti-tumor activity have been successfully translated from basic science studies into clinical care (Byrne et al., 2015; Sharma and Allison, 2015; Shin and Ribas, 2015; Callahan et al., 2016). Although, antibodies directed against CTLA- 4 and PD- 1 are the most prominent examples of therapies that have generated clinical responses in human malignancy, there is significant interest in identifying additional inhibitory regulators of $\mathrm{T}$ cells to combine with existing approaches and to use in instances where blockade of PD-1 and other immune checkpoints is ineffective (Restifo et al., 2016). We focused our studies on DGK $\zeta$, since that enzyme appears to represent the dominant isoform in $\mathrm{T}$ cells, based on a direct comparison of TCR signal strength between T cells deficient in either DGK $\alpha$ or DGK $\zeta$ (Joshi et al., 2013). Using an EL4-ova subcutaneous model system to permit tracking of immune responses, we observed that $\mathrm{DGK} \zeta^{-/-}$mice had an increased frequency of tumor rejection, along with a trend toward increased number of tumor-specific $\mathrm{CD}^{+}{ }^{+} \mathrm{T}$ cells (Riese et al., 2011). Additionally, we demonstrated that adoptively transferred naïve (Riese et al., 2011) or activated (Riese et al., 2013) tumorspecific effector $\mathrm{T}$ cells displayed increased activation by tumor and resultant inhibition of tumor growth. While these studies relied on strong-antigen driven tumor models, it is likely that loss of DGKs also enhances T cell anti-tumor activity in tumors with low-grade antigens, since DAG-mediated activation of RasGRP1 regulates the threshold for T cell activation (Das et al., 2009), and earlier studies implicated a role for Ras in Jurkat $\mathrm{T}$ cell activation mediated by low grade TCR stimulus (Perez de Castro et al., 2004).

$\mathrm{DGK} \alpha$ has also been evaluated as a potential target to improve $T$ cell activity against tumor, based on the observation that DGK $\alpha$ is upregulated in certain inhibited $\mathrm{T}$ cell conditions, such as anergy (Zha et al., 2006), and that DGK $\alpha$ is upregulated in tumorinfiltrating lymphocytes in human renal cell carcinoma (Prinz et al., 2012). For instance, our own study using adoptive transfer of CAR (chimeric antigen receptor)-T cells demonstrated similar increases in efficacy (compared to wild type $\mathrm{T}$ cells) between $\mathrm{T}$ cells deficient in DGK $\alpha$ or DGK $\zeta$ in the treatment of murine mesothelioma (Riese et al., 2013). Additionally, a study testing the importance of DGK $\alpha$ in glioblastoma multiforme (GBM) cells found that concurrent administration of the relatively nonspecific DGK $\alpha$ inhibitor R59022 resulted in decreased growth of intracranially injected GBM tumors. Although, a preponderance of evidence suggested that the decreased tumor growth in this model resulted from inhibition of DGK $\alpha$ within the tumor cells, modulation of immune activity was not assessed, and could have been contributory (Dominguez et al., 2013). DGKs also play a role in limiting the activity of NK cells isolated from tumors in patients with renal cell carcinoma, since the addition of either IL-2 or DGK inhibitor (R59022) to culture media improves the impaired function of tumor-associated NK cells (Prinz et al., 2014). Recently, a more specific inhibitor for DGK $\alpha$ has been developed that may be useful to extend these studies into additional tumor models (Liu et al., 2016). Although a direct comparison has not to-date been performed comparing tumor growth in $\mathrm{DGK} \alpha^{-/-}$and $\mathrm{DGK} \zeta^{-/-}$mice, future studies will undoubtedly provide additional comparisons between the two genotypes with respect to $\mathrm{T}$ cell anti-tumor immunity.

\section{MECHANISM OF ENHANCED T CELL ANTI-TUMOR ACTIVITY IN

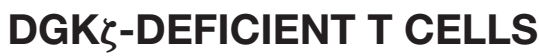

Enhanced anti-tumor activity observed in DGK $\zeta$-deficient $\mathrm{T}$ cells was initially thought to result from increased cytokine production generated after TCR stimulation; however, it is clear that intrinsic insensitivity to inhibitory signals in the tumor microenvironment is also an important determinant. In broad terms, $\mathrm{T}$ cell inhibitory factors can be broadly separated into two groups: those that inhibit $\mathrm{T}$ cells by directly inhibiting proximal TCR signal transduction, and those that inhibit T cells independent of attenuation of TCR signaling. Examples 
of immunosuppressant pathways that facilitate direct inhibition of TCR signaling include PD-1 (Chemnitz et al., 2004; Parry et al., 2005; Yokosuka et al., 2012), Lag3 (Okazaki et al., 2011), Prostglandin $\mathrm{E}_{2}\left(\mathrm{PGE}_{2}\right)$ (Wehbi and Taskén, 2016), adenosine 2A receptor (Linnemann et al., 2009; Linden and Cekic, 2012), and as we have recently identified, TGF $\beta$ (Arumugam et al., 2015; Newman et al., 2016). Whereas, PD-1 and TGF $\beta$ inhibit TCR signaling by directly or indirectly recruiting inhibitory tyrosine phosphatases, such as SHP-1 or SHP-2 (Src homology region 2 domain-containing phosphatase-1/2) to the cell surface, adenosine $2 \mathrm{~A}$, and $\mathrm{PGE}_{2}$ receptors activate protein kinase $\mathrm{A}$ (PKA) leading to Csk-mediated inhibition of the proximal activating tyrosine kinase Lck (Newick et al., 2016). In contrast, Lag3 appears to oppose TCR signaling via a KIEELE motif that acts through an unclear mechanism (Freeman and Sharpe, 2012). In either case, these inhibitory factors act to oppose activation events facilitated by proximal tyrosine protein kinases, such as Lck or Zap-70, that are responsible for initiating TCR signal cascades and are upstream of DAG generation. In contrast are inhibitory factors that act predominantly by inhibiting $\mathrm{T}$ cells independent of TCR activation and DAG generation. These include a subset of immune checkpoint receptors, such as Tim3 (Jones et al., 2008; Lee et al., 2011), and CTLA-4. Although some reports have suggested direct proximal inhibition of TCR mediated by CTLA-4 (Lee et al., 1998), CTLA-4 more likely functions predominantly as a sink to sequester CD80 and CD86, the ligands of the co-stimulatory molecule CD28 (Green et al., 1994; Walunas et al., 1996; van der Merwe et al., 1997; Collins et al., 2002). T cells deficient in DGKs may demonstrate differential sensitivity to inhibition mediated by dependently or independently of TCR signaling (Figure 1, Table 1). For instance, a test of numerous $\mathrm{T}$ cell inhibitory pathways revealed that, in contrast to wild type $\mathrm{T}$ cells, $\mathrm{T}$ cells lacking DGK $\zeta$ demonstrate reduced inhibition of IFN $\gamma$ production in the presence of high concentrations of TGF $\beta$, Prostaglandin $\mathrm{E}_{2}$ $\left(\mathrm{PGE}_{2}\right)$ or adenosine (Riese et al., 2013). This suggests that one can predict, in broad terms, how DGK-deficient $\mathrm{T}$ cells will respond to various immunosuppressive pathways within the tumor microenvironment, in that one would anticipate DGKdeficient $\mathrm{T}$ cells to be insensitive to inhibitors that directly attenuate TCR signaling, such as PD-1 or Lag3, but sensitive to inhibitory pathways that do not directly interfere with TCR signaling, such as Tim3 or CTLA-4. This model also predicts which immune targets might be optimally paired with agents that block DGKs, such that one would anticipate little synergy with direct regulators of TCR signaling, but potential excellent synergy with TCR-independent inhibitors. Experiments are currently ongoing to test these hypotheses.

\section{POTENTIAL ISSUES ARISING FROM TARGETING DGKS}

The diverse set of cellular functions governed by DAG and PA, including signal transduction (Mérida et al., 2008), lipid biogenesis (Shulga et al., 2013), and membrane trafficking (Cho and Stahelin, 2005), presents challenges for broadly targeting
DGK activity therapeutically, especially since the enzymatic specificity of the 10 mammalian DGKs is highly conserved, with the exception of DGKE (Jennings et al., 2015). Thus, isolation of a compound with specificity toward an individual isoform may prove difficult, a problem exacerbated by the paucity of structural information available about eukaryotic DGKs. Although, a prokaryotic form of DGK has been solved structurally (Li et al., 2013), it is sufficiently divergent from eukaryotic isoforms that it provides little value in predicting active site topography of eukaryotic DGKs. For instance, prokaryotic DGKA is not limited to enzymatic activity against lipids, but can also catalyze reactions using glycerol and water as substrates for phosphorylation (Ullrich et al., 2011). Therefore, approaches to target noncatalytic domains of DGK $\zeta$ may provide the best means to achieve isoform specificity. The structural domains of DGK $\zeta$ have been well defined, and include a C1 domain, a MARCKS domain, an ankyrin repeat domain, and a C-terminal PDZ-binding domain (Joshi and Koretzky, 2013). Of these domains, only the MARCKS domain and ankyrin repeat domain are unique to DGK $\zeta$ among the 10 DGK family members (Joshi and Koretzky, 2013). Furthermore, only the MARCKS domain, a substrate for serine/threonine phosphorylation by $\mathrm{PKC} \alpha$ (Topham et al., 1998), is required for DGK $\zeta$ function (Santos et al., 2002). Thus, targeting the MARCKS domain may be an effective strategy for therapeutic targeting of $\mathrm{DGK} \zeta$, in a manner that confers specificity.

Apart from concerns with isotype specificity, therapeutic targeting of DGK $\alpha$ and DGK $\zeta$ could result in deleterious "ontarget" effects, such as enhanced cellular proliferation and autoimmunity. As expected, mice with deletions of both DGK $\alpha$ and DGK $\zeta$ generate $\mathrm{T}$ cells with enhanced TCR signaling downstream of DAG, as well as more potent effector functions after in vitro stimulation relative to single knockouts or wild type T cells (Guo et al., 2008; Riese et al., 2013). However, the activated level of Ras/Erk signal transduction in double knockout mice (DKO) results in thymic lymphomagenesis (Guo et al., 2008). This pro-malignant potential of enhanced DAG signaling is consistent with data from human patients with $\mathrm{T}$ cell acute lymphoblastic leukemia (T-ALL), in which RasGRP1, the Ras activating protein activated by DAG, has been found to be frequently overexpressed (Hartzell et al., 2013). Thus, caution must be used if DGK germline deletion (e.g., using CRISPR-based approaches) is used as a means to target DGKs in adoptive $\mathrm{T}$ cell therapies. Generating auto-immune disease may also be an issue when targeting DGKs. Although mice deficient in DGK $\alpha, \mathrm{DGK} \zeta$, or both do not develop overt autoimmunity, it is likely that the mice would develop enhanced $\mathrm{T}$ cell responses in autoimmune models such as experimental autoimmune encephalitis (EAE), especially given the role DGKs play in limiting activation of Mnk1/2-mediated activation and development of encephalitis in the EAE model (Gorentla et al., 2013). A possible explanation for the lack of overt autoimmunity in DGK $\zeta$ or DKO mice may be the concurrent enhanced generation of natural $\mathrm{T}$ regs in these mice (Joshi et al., 2013), although this remains speculative, and raises the additional consideration that thymic development of $\mathrm{T}$ cells may be impacted by manipulation of DGK activity. For instance, constitutive expression of a membrane-bound form of DGK $\alpha$ 


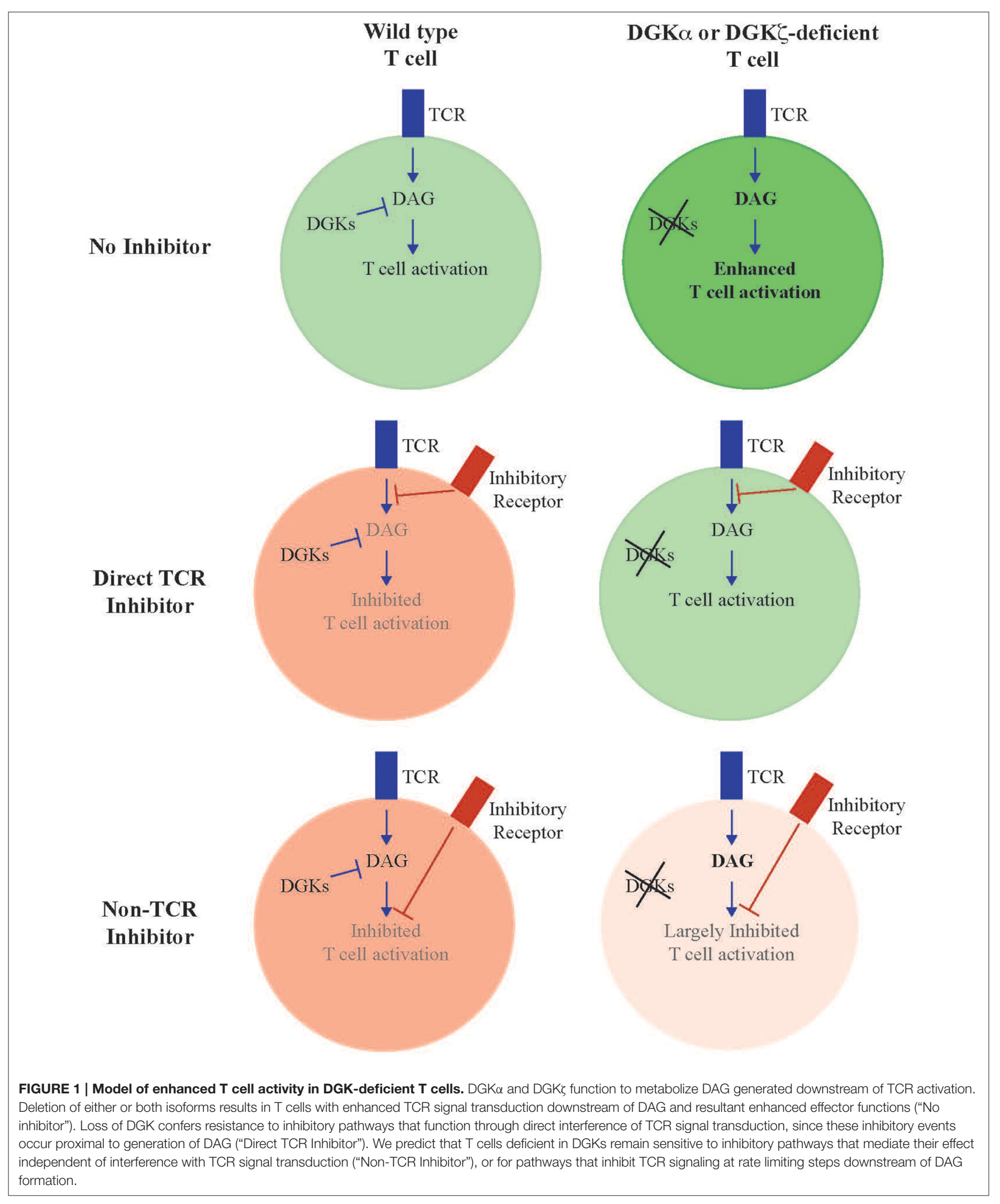


TABLE 1 | Relative insensitivity to inhibitory stimuli of CD8+ T cells.

\begin{tabular}{|c|c|c|c|c|}
\hline \multirow[t]{2}{*}{ Inhibitory stimuli/receptor } & \multicolumn{2}{|c|}{$\begin{array}{l}\text { Inhibitor-mediated fold } \downarrow \text { in } \\
\text { IFN } \gamma \text { by CD8+ T cell }\end{array}$} & \multirow[t]{2}{*}{$\begin{array}{l}\text { Does inhibitory pathway directly } \\
\text { impact TCR signaling? }\end{array}$} & \multirow[t]{2}{*}{ References } \\
\hline & WT & $\mathrm{DGK}_{\zeta^{-1-}}$ & & \\
\hline TGF $\beta$ & $35 x$ & $1 x$ & Yes & Arumugam et al., 2015 \\
\hline $\mathrm{PGE}_{2}$ & $2 x$ & $1.5 x$ & Yes & Riese et al., 2013 \\
\hline Adenosine & $2 x$ & $1.2 x$ & Yes & Riese et al., 2013 \\
\hline PD-1 & $4 x$ & Unknown & Yes & Parry et al., 2005 \\
\hline Lag3 & $2 x$ & Unknown & Yes & Hannier et al., 1998; Huang et al., 2015 \\
\hline Tim-3 & None & Unknown & No & Lee et al., 2011 \\
\hline CTLA-4 & $2 x$ & Unknown & Uncertain & $\begin{array}{l}\text { Krummel and Allison, 1995; Walunas and } \\
\text { Bluestone, } 1998\end{array}$ \\
\hline
\end{tabular}

leads to accumulation of immature CD8+ "single positive" $\mathrm{T}$ cells within the thymus in addition to peripheral lymphopenia (Almena et al., 2013), and DKO mice demonstrate a severe impairment in thymic development of invariant NKT cells, a subset of innate T cells (Shen et al., 2011). Ongoing experiments are needed to test whether DGK-deficient mice will develop more severe disease than wild type counterparts after autoimmune challenges, and to determine whether subtle alterations are present in the thymic development of other conventional $\mathrm{T}$ cell subsets.

\section{CONCLUSIONS}

As immunotherapeutic approaches come to the forefront of cancer treatment, there is an increased need to evaluate proteins and molecules that inhibit the immune system, especially in $\mathrm{T}$ cells. Diacylglycerol kinases should warrant a high degree of consideration in these targeting strategies, ideally with the development of small molecule inhibitors. In the meanwhile, it may be advantageous to move forward with gene manipulation in adoptive cellular therapies. The ability to very specifically target DGKs within only the transferred T cells will minimize systemic side effects. It will also be possible to include suicide genes to

\section{REFERENCES}

Almena, M., Andrada, E., Liebana, R., and Merida, I. (2013). Diacylglycerol metabolism attenuates $\mathrm{T}$-cell receptor signaling and alters thymocyte differentiation. Cell Death Dis. 4, e912. doi: 10.1038/cddis.2013.396

Arumugam, V., Bluemn, T., Wesley, E., Schmidt, A. M., Kambayashi, T., Malarkannan, S., et al. (2015). TCR signaling intensity controls CD8+ $\mathrm{T}$ cell responsiveness to TGF- $\beta$. J. Leukoc. Biol. 98, 703-712. doi: 10.1189/jlb.2HIMA1214-578R

Baldanzi, G., Pighini, A., Bettio, V., Rainero, E., Traini, S., Chianale, F., et al. (2011). SAP-mediated inhibition of diacylglycerol kinase $\alpha$ regulates TCR-induced diacylglycerol signaling. J. Immunol. 187, 5941-5951. doi: 10.4049/jimmunol.1002476

Byrne, K. T., Vonderheide, R. H., Jaffee, E. M., and Armstrong, T. D. (2015). Special conference on tumor immunology and immunotherapy: a new chapter. Cancer Immunol. Res. 3, 590-597. doi: 10.1158/2326-6066.CIR15-0106 enable destruction of the transferred $\mathrm{T}$ cells, should it become necessary. A better understanding of the changes that result from acute and long-term targeting of DGKs should help discern the effectiveness of this strategy both alone, and in combination with other therapies designed to induce immune cell activation.

\section{AUTHOR CONTRIBUTIONS}

All authors contributed to the conception and design of the manuscript and contributed writing to the paper.

\section{FUNDING}

Funding provided by NIH K08 CA151893 (MR), NIH K08 CA163941 (EM), American Cancer Society (MR), Kathy Duffey Fogerty Family Foundation (MR), HRHM Program of MACC Fund (BJ).

\section{ACKNOWLEDGMENTS}

The authors thank Subramaniam Malarkannan (Medical College of Wisconsin and Blood Center of Wisconsin, Milwaukee, WI) for critical review of the manuscript.

Callahan, M. K., Postow, M. A., and Wolchok, J. D. (2016). Targeting $\mathrm{T}$ cell co-receptors for cancer therapy. Immunity 44, 1069-1078. doi: 10.1016/j.immuni.2016.04.023

Chemnitz, J. M., Parry, R. V., Nichols, K. E., June, C. H., and Riley, J. L. (2004). SHP-1 and SHP-2 associate with immunoreceptor tyrosine-based switch motif of programmed death 1 upon primary human $\mathrm{T}$ cell stimulation, but only receptor ligation prevents T cell activation. J. Immunol. 173, 945-954.

Chibalin, A. V., Leng, Y., Vieira, E., Krook, A., Björnholm, M., Long, Y. C., et al. (2008). Downregulation of diacylglycerol kinase delta contributes to hyperglycemia-induced insulin resistance. Cell 132, 375-386. doi: 10.1016/j.cell.2007.12.035

Cho, W., and Stahelin, R. V. (2005). Membrane-protein interactions in cell signaling and membrane trafficking. Annu. Rev. Biophys. Biomol. Struct. 34, 119-151. doi: 10.1146/annurev.biophys.33.110502.133337

Collins, A. V., Brodie, D. W., Gilbert, R. J. C., Iaboni, A., Manso-Sancho, R., Walse, B., et al. (2002). The interaction properties of costimulatory molecules revisited. Immunity 17, 201-210. 
Das, J., Ho, M., Zikherman, J., Govern, C., Yang, M., Weiss, A., et al. (2009). Digital signaling and hysteresis characterize ras activation in lymphoid cells. Cell 136, 337-351. doi: 10.1016/j.cell.2008.11.051

Dominguez, C. L., Floyd, D. H., Xiao, A., Mullins, G. R., Kefas, B. A., Xin, W., et al. (2013). Diacylglycerol kinase $\alpha$ is a critical signaling node and novel therapeutic target in glioblastoma and other cancers. Cancer Discov. 3, 782-797. doi: 10.1158/2159-8290.CD-12-0215

Eichmann, T. O., and Lass, A. (2015). DAG tales: the multiple faces of diacylglycerol-stereochemistry, metabolism, and signaling. Cell. Mol. Life Sci. 72, 3931-3952. doi: 10.1007/s00018-015-1982-3

Freeman, G. J., and Sharpe, A. H. (2012). A new therapeutic strategy for malaria: targeting T cell exhaustion. Nat. Immunol. 13, 113-115. doi: 10.1038/ni.2211

Gorentla, B. K., Krishna, S., Shin, J., Inoue, M., Shinohara, M. L., Grayson, J. M., et al. (2013). Mnk1 and 2 are dispensable for T cell development and activation but important for the pathogenesis of experimental autoimmune encephalomyelitis. J. Immunol. 190, 1026-1037. doi: 10.4049/jimmunol.1200026

Green, J. M., Noel, P. J., Sperling, A. I., Walunas, T. L., Gray, G. S., Bluestone, J. A., et al. (1994). Absence of B7-dependent responses in CD28-deficient mice. Immunity 1, 501-508.

Guo, R., Wan, C.-K., Carpenter, J. H., Mousallem, T., Boustany, R.-M. N., Kuan, C.-T., et al. (2008). Synergistic control of T cell development and tumor suppression by diacylglycerol kinase alpha and zeta. Proc. Natl. Acad. Sci. U.S.A. 105, 11909-11914. doi: 10.1073/pnas.0711856105

Hannier, S., Tournier, M., Bismuth, G., and Triebel, F. (1998). CD3/TCR complexassociated lymphocyte activation gene-3 molecules inhibit CD3/TCR signaling. J. Immunol. 161, 4058-4065.

Hartzell, C., Ksionda, O., Lemmens, E., Coakley, K., Yang, M., Dail, M., et al. (2013). Dysregulated RasGRP1 responds to cytokine receptor input in T cell leukemogenesis. Sci. Signal. 6, ra21. doi: 10.1126/scisignal.2003848

Huang, R. Y., Eppolito, C., Lele, S., Shrikant, P., Matsuzaki, J., and Odunsi, K. (2015). LAG3 and PD1 co-inhibitory molecules collaborate to limit CD8+ T cell signaling and dampen antitumor immunity in a murine ovarian cancer model. Oncotarget 6, 27359-27377. doi: 10.18632/oncotarget.4751

Jennings, W., Doshi, S., D’Souza, K., and Epand, R. M. (2015). Molecular properties of diacylglycerol kinase-epsilon in relation to function. Chem. Phys. Lipids 192, 100-108. doi: 10.1016/j.chemphyslip.2015.06.003

Jones, R. B., Ndhlovu, L. C., Barbour, J. D., Sheth, P. M., Jha, A. R., Long, B. R., et al. (2008). Tim-3 expression defines a novel population of dysfunctional $\mathrm{T}$ cells with highly elevated frequencies in progressive HIV-1 infection. J. Exp. Med. 205, 2763-2779. doi: 10.1084/jem.20081398

Joshi, R. P., and Koretzky, G. A. (2013). Diacylglycerol kinases: regulated controllers of T cell activation, function, and development. Int. J. Mol. Sci. 14, 6649-6673. doi: 10.3390/ijms14046649

Joshi, R. P., Schmidt, A. M., Das, J., Pytel, D., Riese, M. J., Lester, M., et al. (2013). The $\zeta$ isoform of diacylglycerol kinase plays a predominant role in regulatory T cell development and TCR-mediated ras signaling. Sci. Signal. 6, ra102. doi: 10.1126/scisignal.2004373

Krishna, S., and Zhong, X. (2013). Role of diacylglycerol kinases in T cell development and function. Crit. Rev. Immunol. 33, 97-118.

Krummel, M. F., and Allison, J. P. (1995). CD28 and CTLA-4 have opposing effects on the response of T cells to stimulation. J. Exp. Med. 182, 459-465.

Lee, J., Su, E. W., Zhu, C., Hainline, S., Phuah, J., Moroco, J. A., et al. (2011). Phosphotyrosine-dependent coupling of Tim-3 to T-cell receptor signaling pathways. Mol. Cell. Biol. 31, 3963-3974. doi: 10.1128/MCB.05297-11

Lee, K. M., Chuang, E., Griffin, M., Khattri, R., Hong, D. K., Zhang, W., et al. (1998). Molecular basis of T cell inactivation by CTLA-4. Science 282, 2263-2266.

Li, D., Lyons, J. A., Pye, V. E., Vogeley, L., Aragão, D., Kenyon, C. P., et al. (2013). Crystal structure of the integral membrane diacylglycerol kinase. Nature 497, 521-524. doi: 10.1038/nature12179

Linden, J., and Cekic, C. (2012). Regulation of lymphocyte function by adenosine. Arterioscler. Thromb. Vasc. Biol. 32, 2097-2103. doi: 10.1161/ATVBAHA.111.226837

Linnemann, C., Schildberg, F. A., Schurich, A., Diehl, L., Hegenbarth, S. I., Endl, E., et al. (2009). Adenosine regulates CD8 T-cell priming by inhibition of membrane-proximal T-cell receptor signalling. Immunology 128, e728-e737. doi: 10.1111/j.1365-2567.2009.03075.x
Liu, K., Kunii, N., Sakuma, M., Yamaki, A., Mizuno, S., Sato, M., et al. (2016). A novel diacylglycerol kinase $\alpha$-selective inhibitor, CU-3, induces cancer cell apoptosis and enhances immune response. J. Lipid Res. 57, 368-379. doi: 10.1194/jlr.M062794

Mérida, I., Avila-Flores, A., and Merino, E. (2008). Diacylglycerol kinases: at the hub of cell signalling. Biochem. J. 409, 1-18. doi: 10.1042/BJ20071040

Newick, K., O’Brien, S., Sun, J., Kapoor, V., Maceyko, S., Lo, A., et al. (2016). Augmentation of CAR T-cell trafficking and anti-tumor efficacy by blocking protein kinase A. Localization 4, 541-551. doi: 10.1158/2326-6066.CIR-15-0263

Newman, D. K., Fu, G., Adams, T., Arumugam, V., Bluemn, T., and Riese, M. J. (2016). An unexpected role for PECAM-1 in TGF beta-mediated inhibition of T cell function. Sci. Signal. 9, 1-12.

Okazaki, T., Okazaki, I.-M., Wang, J., Sugiura, D., Nakaki, F., Yoshida, T., et al. (2011). PD-1 and LAG-3 inhibitory co-receptors act synergistically to prevent autoimmunity in mice. J. Exp. Med. 208, 395-407. doi: 10.1084/jem.20100466

Olenchock, B. A., Guo, R., Carpenter, J. H., Jordan, M., Topham, M. K., Koretzky, G. A., et al. (2006). Disruption of diacylglycerol metabolism impairs the induction of T cell anergy. Nat. Immunol. 7, 1174-1181. doi: 10.1038/ni1400

Parry, R. V., Chemnitz, J. M., Frauwirth, K. A., Lanfranco, A. R., Braunstein, I., Kobayashi, S. V., et al. (2005). CTLA-4 and PD-1 receptors inhibit Tcell activation by distinct mechanisms. Mol. Cell. Biol. 25, 9543-9553. doi: 10.1128/MCB.25.21.9543-9553.2005

Perez de Castro, I., Bivona, T. G., Philips, M. R., and Pellicer, A. (2004). Ras activation in Jurkat $\mathrm{T}$ cells following low-grade stimulation of the T-cell receptor is specific to N-Ras and occurs only on the Golgi apparatus. Mol. Cell. Biol. 24, 3485-3496.

Prinz, P. U., Mendler, A. N., Brech, D., Masouris, I., Oberneder, R., and Noessner, E. (2014). NK-cell dysfunction in human renal carcinoma reveals diacylglycerol kinase as key regulator and target for therapeutic intervention. Int. J. Cancer 135, 1832-1841. doi: 10.1002/ijc.28837

Prinz, P. U., Mendler, A. N., Masouris, I., Durner, L., Oberneder, R., and Noessner, E. (2012). High DGK- $\alpha$ and disabled MAPK pathways cause dysfunction of human tumor-infiltrating CD8 $+\mathrm{T}$ cells that is reversible by pharmacologic intervention. J. Immunol. 188, 5990-6000. doi: 10.4049/jimmunol.1103028

Quann, E. J., Liu, X., Altan-Bonnet, G., and Huse, M. (2011). A cascade of protein kinase $\mathrm{C}$ isozymes promotes cytoskeletal polarization in T cells. Nat. Immunol. 12, 647-654. doi: 10.1038/ni.2033

Restifo, N. P., Smyth, M. J., and Snyder, A. (2016). Acquired resistance to immunotherapy and future challenges. Nat. Rev. Cancer 16, 121-126. doi: $10.1038 / \mathrm{nrc} .2016 .2$

Riese, M. J., Grewal, J., Das, J., Zou, T., Patil, V., Chakraborty, A. K., et al. (2011). Decreased diacylglycerol metabolism enhances ERK activation and augments CD8+ T cell functional responses. J. Biol. Chem. 286, 5254-5265. doi: 10.1074/jbc.M110.171884

Riese, M. J., Wang, L.-C. S., Moon, E. K., Joshi, R. P., Ranganathan, A., June, C. H., et al. (2013). Enhanced effector responses in activated CD8+ $\mathrm{T}$ cells deficient in diacylglycerol kinases. Cancer Res. 73, 3566-3577. doi: 10.1158/0008-5472.CAN-12-3874

Ruffo, E., Malacarne, V., Larsen, S. E., Das, R., Patrussi, L., Wülfing, C., et al. (2016). Inhibition of diacylglycerol kinase $\alpha$ restores restimulation-induced cell death and reduces immunopathology in XLP-1. Sci. Transl. Med. 8, 321ra7. doi: 10.1126/scitranslmed.aad1565

Sanjuán, M. A., Jones, D. R., Izquierdo, M., and Mérida, I. (2001). Role of diacylglycerol kinase alpha in the attenuation of receptor signaling. J. Cell Biol. $153,207-220$.

Santos, T., Carrasco, S., Jones, D. R., Mérida, I., and Eguinoa, A. (2002). Dynamics of diacylglycerol kinase zeta translocation in living T-cells. Study of the structural domain requirements for translocation and activity. J. Biol. Chem. 277, 30300-30309. doi: 10.1074/jbc.M200999200

Schmidt, A. M., Zou, T., Joshi, R. P., Leichner, T. M., Pimentel, M. A., Sommers, C. L., et al. (2013). Diacylglycerol kinase $\zeta$ limits the generation of natural regulatory T cells. Sci. Signal. 6, ra101. doi: 10.1126/scisignal.2004411

Sharma, P., and Allison, J. P. (2015). The future of immune checkpoint therapy. Science 348, 56-61. doi: 10.1126/science.aaa8172

Shen, S., Wu, J., Srivatsan, S., Gorentla, B. K., Shin, J., Xu, L., et al. (2011). Tight regulation of diacylglycerol-mediated signaling is critical for proper invariant NKT cell development. J. Immunol. 187, 2122-2129. doi: 10.4049/jimmunol.1100495 
Shin, D. S., and Ribas, A. (2015). The evolution of checkpoint blockade as a cancer therapy: what"s here, what"s next? Curr. Opin. Immunol. 33, 23-35. doi: 10.1016/j.coi.2015.01.006

Shulga, Y. V., Loukov, D., Ivanova, P. T., Milne, S. B., Myers, D. S., Hatch, G. M., et al. (2013). Diacylglycerol kinase delta promotes lipogenesis. Biochemistry 52, 7766-7776. doi: 10.1021/bi401178y

Topham, M. K., Bunting, M., Zimmerman, G. A., McIntyre, T. M., Blackshear, P. J., and Prescott, S. M. (1998). Protein kinase C regulates the nuclear localization of diacylglycerol kinase-zeta. Nature 394, 697-700. doi: 10.1038/29337

Ullrich, S. J., Hellmich, U. A., Ullrich, S., and Glaubitz, C. (2011). Interfacial enzyme kinetics of a membrane bound kinase analyzed by real-time MASNMR. Nat. Chem. Biol. 7, 263-270. doi: 10.1038/nchembio.543

van der Merwe, P. A., Bodian, D. L., Daenke, S., Linsley, P., and Davis, S. J. (1997). CD80 (B7-1) binds both CD28 and CTLA-4 with a low affinity and very fast kinetics. J. Exp. Med. 185, 393-403.

Walunas, T. L., Bakker, C. Y., and Bluestone, J. A. (1996). CTLA-4 ligation blocks CD28-dependent T cell activation. J. Exp. Med. 183, 2541-2550.

Walunas, T. L., and Bluestone, J. A. (1998). CTLA-4 regulates tolerance induction and $\mathrm{T}$ cell differentiation in vivo. J. Immunol. 187, 3466-3474.

Wehbi, V. L., and Taskén, K. (2016). Molecular mechanisms for cAMP-mediated immunoregulation in $\mathrm{T}$ cells - role of anchored protein Kinase A signaling units. Front. Immunol. 7:222. doi: 10.3389/fimmu.2016.00222

Yang, J., Zhang, P., Krishna, S., Wang, J., Lin, X., Huang, H., et al. (2016). Unexpected positive control of NFKB and miR-155 by DGK $\alpha$ and $\zeta$ ensures effector and memory CD8+ T cell differentiation. Oncotarget. 7, 33744-33764. doi: 10.18632/oncotarget.8164

Yokosuka, T., Takamatsu, M., Kobayashi-Imanishi, W., Hashimoto-Tane, A., Azuma, M., and Saito, T. (2012). Programmed cell death 1 forms negative costimulatory microclusters that directly inhibit $\mathrm{T}$ cell receptor signaling by recruiting phosphatase SHP2. J. Exp. Med. 209, 1201-1217. doi: 10.1084/jem.20112741

Zha, Y., Marks, R., Ho, A. W., Peterson, A. C., Janardhan, S., Brown, I., et al. (2006). T cell anergy is reversed by active Ras and is regulated by diacylglycerol kinase-alpha. Nat. Immunol. 7, 1166-1173. doi: 10.1038/ni1394

Zhong, X.-P., Hainey, E. A., Olenchock, B. A., Jordan, M. S., Maltzman, J. S., Nichols, K. E., et al. (2003). Enhanced T cell responses due to diacylglycerol kinase zeta deficiency. Nat. Immunol. 4, 882-890. doi: 10.1038/ ni958

Zhong, X.-P., Hainey, E. A., Olenchock, B. A., Zhao, H., Topham, M. K., and Koretzky, G. A. (2002). Regulation of T cell receptor-induced activation of the Ras-ERK pathway by diacylglycerol kinase zeta. J. Biol. Chem. 277, 31089-31098. doi: 10.1074/jbc.M203818200

Conflict of Interest Statement: The authors declare that the research was conducted in the absence of any commercial or financial relationships that could be construed as a potential conflict of interest.

MR and SA are co-holders of a pending patent application on targeting DGKs for adoptive cellular therapies.

Copyright (C) 2016 Riese, Moon, Johnson and Albelda. This is an open-access article distributed under the terms of the Creative Commons Attribution License (CC BY). The use, distribution or reproduction in other forums is permitted, provided the original author(s) or licensor are credited and that the original publication in this journal is cited, in accordance with accepted academic practice. No use, distribution or reproduction is permitted which does not comply with these terms. 